\title{
The co-evolution of technological promises, modelling, policies and climate change targets
}

\author{
Duncan McLaren* and Nils Markusson \\ Lancaster Environment Centre, Lancaster University (*corresponding author: d.mclaren@lancaster.ac.uk) \\ The nature and framing of climate targets in international politics has changed substantially since their \\ early expressions in the 1980s. Here we describe their evolution in five phases from 'climate \\ stabilisation' to specific 'temperature outcomes', co-evolving with wider climate politics and policy, \\ modelling methods and scenarios, and technological promises (from nuclear power to carbon removal). \\ We argue that this co-evolution has enabled policy prevarication, leaving mitigation poorly delivered, \\ yet the technological promises often remain buried in the models used to inform policy. We conclude \\ with a call to recognise and break this pattern to unleash more effective and just climate policy.
}

\section{Introduction}

Contemporary technological proposals for responding to climate change involve giant carbon sucking machines, ice-restoration using millions of wind-powered pumps, and solar radiation reflection with stratospheric aerosols. Current debate treats these as unproven novelties, often contrasted with more established approaches to meeting objective science-based targets. Here we argue rather that such proposals are the latest incarnation of 'technologies of prevarication': technological promises elicited by climate politics and policy. We describe a history of such promises, mediated through developing practices of modelling that shape both targets and other policies, and the imagined technologies needed to meet them in an ongoing cycle which repeatedly avoids transformative social and economic change.

We briefly map the history of climate targets in five phases (Figure 1), showing how the overarching international goal of 'avoiding dangerous climate change' has been reinterpreted and differently represented in the light of new modelling methods and the technological promises they have shaped. We suggest that the changing framings of targets and associated metrics between these phases reflected not only growing computational power for more detailed modelling, but also novel modelling practices more directly linking emissions and climate outcomes. These patterns are not tightly correlated, as different cultural, technological and political processes move at different speeds (so, for example the forms of target adopted in (inter)governmental climate policy typically lag behind those in scientific analysis and citizen campaigns). Nonetheless we argue that this history - illustrated here with national examples drawn mainly from the UK - is indicative of an overall dynamic which should give climate scientists and policy-makers pause for thought before pursuing yet another round of technological promises without social transformation in the hope of averting dangerous climate change.

The largely stepwise sequence we have identified and labelled with characteristic policy goals begins with "stabilization", followed by a focus on "percentage emissions reductions", shifting to "atmospheric concentrations" (expressed in parts per million), "cumulative budgets" (in tonnes of carbon dioxide), and currently "outcome temperatures". When we associate a particular target framing with a particular period we are not claiming that it was only expressed then, nor that it was hegemonic within the broad public discourse of the period, merely that the policy debate about targets at that time was noticeably framed primarily in those terms, while previous formulations retreated from the public eye.

Each of the following sections summarises the ways and terms in which the policy, and any associated target, is framed, its proponents, and when and how it emerged; with reference to the associated envisioned technologies and policies, and the modelling practices and scenarios deployed to inform these framings and policy discussions; and indicates ways in which these developments co-evolved. Each is 
located in time by reference to key events in international climate negotiations, and illustrated in figure 1, which sketches some of the main elements and interactions involved.

[insert figure 1 around here]

\section{Stabilization (Rio 1992)}

In the first phase (Figure 1a), despite a brief flirtation with emissions reduction targets in the late 1980s ${ }^{1}$, at Rio, the UN settled on a goal of 'stabilising atmospheric concentrations of GHGs at a level commensurate with avoiding dangerous anthropogenic climate change' ${ }^{2}$. The setting of this goal followed an era of fairly inchoate climate policy in which diverse responses - whose potential was rarely quantified were suggested, and categories such as mitigation, adaptation and geoengineering were rarely distinguished. The job of turning the goal of 'stabilization' into actionable targets was left to subsequent negotiations, which eventually produced the Kyoto protocol in 1997.

The development of coupled Global Circulation Models and the first integrated assessment models (IAMs) allowed modellers to begin to explore both the impacts of emissions, and the economic costs of particular emissions-reduction techniques, in response to growing policy and activist concerns. These rudimentary models underpinned the earliest scenario exercise of the IPCC (SA90) which focused on prospects for changing energy mix and energy efficiency in a series of increasingly aggressive intervention scenarios ${ }^{3}$. The simplistic nature of the early models perhaps encouraged or elicited broad-brush or large-scale responses whose impacts might be more easily assessed.

Policy responses included interventions such as generally improved energy efficiency, large-scale enhancement of carbon sinks in forests (and amongst some commentators, oceans), and in some countries, new and revived nuclear power programs. The UK created a 'non-fossil-fuel obligation' on electricity utilities, intended to support both nuclear power and renewables. The UK nuclear revival stalled in the face of high costs and public concern, with only one additional plant ever completed, not atypical of a wider pattern in developed economies.

\section{Percentage emissions cuts (Kyoto 1997)}

The subsequent second phase (Figure $1 \mathrm{~b}$ ) - around and especially after the Kyoto summit - was marked by debate over the necessary extent and speed of emissions reductions, typically expressed in terms of percentage reduction targets by particular dates (such as 2005, 2020, or 2050). In part this reflected the scenarios produced by the IPCC in 1992 (IS92) which provided projections of future emissions levels (without intervention) according to different levels of population, income and fossil fuel use ${ }^{3}$, and subsequently in the Special Report on Emissions Scenarios (SRES) in 2000. SRES provided a set of varying forecasts of economic growth and globalisation used to project baseline emissions, against which policies could be measured.

In this period IAMs lacked the capacities to directly relate emissions cuts and outcome temperatures (they were "non-invertable"), but developments in carbon cycle models enabled researchers to relate percentage emission cuts to outcomes described in terms of concentrations of GHGs in parts per million by volume (ppmv). These evolved into the next generation of outcome targets as we will see in Phase 3 , as the SRES scenarios were superseded by the Representative Concentration Pathways (RCPs).

The policy promises and expectations of this period focused on technologies that could reduce emissions from fossil point sources, notably energy efficiency and fuel switching, in part elicited by the framing of the SRES scenarios - relating directly to, and being easy to model within, trends in economic growth and globalisation. In the UK fuel switching dominated practice, linked to policies of energy market liberalisation (and subsequently, and consequently, the renewables obligation on energy utilities), but energy efficiency also received renewed attention as a climate policy with the launch in 2001 of both the Climate Change 
Levy and the Carbon Trust. Neo-liberal market-based approaches were bolstered across the European Union by the launch of the EU emissions trading scheme in 2005.

Contemporary technological expectations also included the emergence of carbon capture and storage (CCS) approaches promising emissions reductions of up to $90 \%$ from fossil power plants. From early proposals in 1990s, especially at MIT, CCS promises and research blossomed in the early 2000s. The IPCC published a CCS special report ${ }^{4}$. The UK established a CCS consortium. CCS was widely adopted in IAM pathways to optimise costs by enabling a slower transition away from fossil power generation, especially coal. But practical development of CCS got little further than research facilities ${ }^{5}$ while the promise of 'CCSreadiness' even facilitated continued construction of new fossil power plants. Efficiency and particularly fuel-switching measures were more widely implemented in practice, but - particularly after accounting for rebound effects - remain far short of the promised prospects even today ${ }^{6}$.

\section{Atmospheric concentrations (Copenhagen 2009)}

In the third phase (Figure 1c), as climate policy struggled to deliver progress, scenarios involving bioenergy with CCS (BECCS) emerged, embedding early conceptual proposals in modelling work directed at finding cost-effective pathways for mitigation in advance of 2007's Fourth Assessment Report (AR4). Like CCS before it, BECCS promised ways to cut the costs of meeting a particular target - slowing the transition even more by its promise to effectively reverse emissions at a future date.

BECCS also implied a capacity to control future atmospheric concentrations of $\mathrm{CO}_{2}$ and its emergence in the models paralleled another reframing of climate goals, subsequently consolidated in the RCP-based analysis for AR5. With growing computer power and improved modelling methods, models and scenarios targeting particular ppm outcomes proliferated. These included many $450 \mathrm{ppm}$ scenarios with large contributions from CCS. In the activist world, 350.org launched in 2007 inspired by James Hansen's work ${ }^{7}$.

This reframing was echoed in California's trend-setting introduction of a carbon intensity portfolio-based emissions performance standard for energy generation in 2007. The UK's Climate Act, enshrining targets in legislation in 2008 , still focused on emissions cuts ( $80 \%$ by 2050 ), but framed them with reference to atmospheric concentrations ('making a fair contribution to a 450 ppm outcome'). By the Copenhagen climate summit in 2009, several countries were framing their proposed positions as contributions to a 450 ppm outcome, although most still talked of percentage emissions reductions, and some had begun to translate concentrations into projected temperature outcomes. Host country Denmark's targeting of a path to $2^{\circ} \mathrm{C}$ was widely criticised as contributing to the failure of the talks.

BECCS promised to open up an affordable $350 \mathrm{ppm}$ pathway, despite appearing largely unnecessary or too expensive to be deployed at scale in a $450 \mathrm{ppm}$ pathway ${ }^{8}$. However the main technological promise in this period remained CCS on fossil energy (FECCS) ${ }^{9}$. But despite the hype, various government incentives and competitions, and the launch of the Global CCS Centre in 2009, practical deployment remained negligible (in part a product of plummeting investment following the global financial crisis, and partly reflecting high costs and public opposition ${ }^{10}$ ).

\section{Cumulative budgets (Durban 2011 and Doha 2012)}

In phase four (Figure 1d), a new concept - the cumulative budget - began to reshape climate targets and climate activism, even before the conceptual dimensions of atmospheric concentrations had been fully digested in the UNFCCC, or in IPCC reporting and modelling (the RCPs began development in 2007, but were only formally launched in 2014). In 2008, the UK began setting periodic five-year 'carbon budgets' under its innovative climate change legislation, demonstrating the policy-relevance of this form of emissions projections. Climate negotiations continued, with the Durban meeting of 2011 presaging a new agreement by 2015, and Doha in 2012 indicating the end of percentage based targets with agreement on a limited second period for the Kyoto Protocol. Temperature outcomes were widely debated, but some 
negotiators argued instead for the pursuit of "a clear limit on GHG concentrations, and consequently a scientifically calculated carbon budget" ${ }^{11}$.

At a similar time, the development of a simple inversion tool in the Magic $\mathrm{C}$ model enabled not only the development of RCPs, but also more sophisticated global carbon budgeting models ${ }^{12-14}$. At a similar time Allen and others argued: "policy targets based on limiting cumulative emissions of carbon dioxide are likely to be more robust to scientific uncertainty than emission-rate or concentration targets" 15: 1163. This provided a critical reinforcement for the emerging importance of negative emissions in climate policy, as both concept or category, and as a group of imaginary technologies which make sense as a tool to manipulate a cumulative budget.

These shifts helped actively construct the idea of negative emissions, and supported the subsequent widespread adoption of NETs - still primarily as BECCS - into IAMs which followed AR4 ${ }^{16,17}$. The inclusion of BECCS in IAMs despite the lack of material emergence of CCS was no coincidence. With emissions continuing to rise, almost the only way to resolve models for the desired atmospheric concentrations or cumulative budgets was to rely on later withdrawals, and compared to other NETs, BECCS was easy to model. In 2014 AR5 incorporated findings from many modelling exercises including BECCs. This allowed modellers to meet what now are the international long-term climate goals even in the face of delayed or otherwise sub-optimal action ${ }^{16}$. Yet most NETs remained as imaginary as CCS, with increasing concern raised about exaggerations of the potential for BECCS ${ }^{18,19}$.

\section{Outcome temperatures (Paris 2015)}

Carbon budgeting never really had a chance to consolidate its position, despite widespread publicity around the idea of the 'trillionth tonne', as policy consolidated around a focus on temperature outcomes, formalised with the Paris accord of 2015, the key event of phase five (Figure 1e).

The idea of $2^{\circ} \mathrm{C}$ as a rough guardrail, although first suggested in the mid-1970s, only became a focal point for policy after Copenhagen ${ }^{20}$. As more powerful models with more detailed resolution regarding regional outcomes explored climate impacts and sensitivity, they enabled quantified probabilities of achieving certain temperature outcomes to be specified. Thus temperatures became more closely tied to carbon budgets and concentrations. At Paris temperatures moved centre-stage as $1.5^{\circ} \mathrm{C}$ became politically live as a more accurate boundary to 'dangerous climate change' especially in the global South (where the more detailed resolution of contemporary modelling had made expected impacts more salient). IAMs became yet more reliant on negative emissions to resolve for $1.5^{\circ} \mathrm{C}$, and other NETs began to feature more heavily as BECCS promises were constrained. In the models, increased future NETs contributions still replace nearterm emissions cuts through the action of cost-optimisation in the face of discounting ${ }^{21}$.

Subsequent to Paris, the long-promised Shared Socioeconomic Pathways (SSPs), a set of broad scenarios mapping more- and less-favourable political, demographic and economic circumstances for mitigation and adaptation, for use in tandem with RCPs, were published. The SSPs provide a multiple set of 'baseline worlds' and are in turn generating new RCPs, including some explicitly exploring 'overshoot' worlds in which temperatures exceed the target before being returned to that level. Such scenarios are particularly conducive to the consideration of negative emissions, whether in technological forms such as Direct Air Capture ${ }^{21}$ or biological forms such as oceans or forests ${ }^{22}$.

The direct linking of cumulative budgets to temperature extended modelling optimisation such that it reaches from technology choices to desired temperatures. Looking ahead, although NETs might retrospectively balance carbon budgets, delayed action would still make a temperature overshoot more likely, constructing a space for an imaginary technology that can act directly to reduce temperatures. Of course such imaginaries already exist in Earth system models, and preliminary promises of solar radiation management (SRM) predate even the emergence of the $2^{\circ} \mathrm{C}$ concept in the $1970 \mathrm{~s}^{23}$. But today they are 
much less speculative ${ }^{24}$. If politicians continue to demand scenarios that deliver $1.5^{\circ} \mathrm{C}$ or even $2^{\circ} \mathrm{C}$ as carbon budgets are consumed, it seems highly likely that modellers will have little choice but to include SRM in the next generation of models.

\section{Discussion}

The sequence set out above highlights a series of technological promises whose parameters and capabilities were at least as much 'constructed' by models and modellers as by engineers and scientists ${ }^{25}$, and which then reshaped political aspirations as much as being elicited by them. This analysis directs attention to the ways in which targets have been reframed or reconstructed over time. Rather than seeing this as purely a logical consequence of better information and growing technical capabilities to link climate outcomes and causes, we understand it as co-evolution between policy and politics, modelling, and science-based technological promises. The technological promises have conditioned, and been conditioned by, the contemporary models, policies and politics, each element thus influencing the subsequent evolution of the others, and vice-versa. In this process the 'evolutionary fitness' of each technological promise is less a product of its (potential) climate impact than a measure of how well it can be modelled, and how well it matches the extant framings of climate policy.

Each technological promise has subsequently become embedded in the models despite limited material delivery at the global scale, in each case transitioning from being an innovative option that promised to enable a cheaper pathway to meet climate targets, to being an unavoidable component of climate action as other contributions were delayed. Critically, in this process, each technological promise has enabled a continued politics of prevarication and inadequate action, by raising expectations of more effective policy options becoming available in the future, in turn justifying existing limited and gradualist policy choices, and thus diminishing the perceived urgency of deploying costly and unpopular, but better understood and tested options for policy in the short term. Prevarication is not necessarily intentional - promises might be made in good-faith, and the delaying effects may only become perceptible with hindsight. But we do fear that each promise has, to some degree, fed systemic 'moral corruption' ${ }^{26}$, in which current elites are enabled to pursue self-serving pathways, while passing off risk onto vulnerable people in the future and in the global South.

This dynamic also interacts repeatedly with more durable political regimes ${ }^{27}$. In this respect, each technological promise, and its articulation in modelling etc., reflected the dominant neo-liberal ideology of the entire period in which market-based and technological innovations that could sustain economic growth were actively preferred over measures that might have threatened liberal individualism, markets and consumerism or required early scrapping of equipment or infrastructure. That for the most part these policies promised future action, rather than immediate sacrifice, clearly made them more palatable to both industry and politicians. The scene was set for this in the earliest phase, with fears of economically costly interventions and President Bush's admonition to the Rio Earth Summit that 'the American way of life is not up for negotiation'. And particularly in the earlier phases several technological promises - such as nuclear power and fuel-switching - did double duty, both maintaining fossil extractivism, and reinforcing a transition away from labour-constrained sources of energy (notably coal), to capital-constrained forms (gas and nuclear) ${ }^{28}$. In these ways technological promises were at least as responsible for the formulation of targets, as they were a product of those target framings.

It would be less worrying if the delays could be understood merely as slowness in practical delivery of technological innovations. But even the earliest promises have materialised at best in limited or geographically patchy forms. Carbon removals by sinks have perhaps even gone backwards, with net releases from land-use today. Nuclear power has been delivered in only a handful of countries, shown little growth for decades and remains contentious almost everywhere. Yet promises of future emissions cuts 
through nuclear power - both fission, and fusion, remain current in the UK and elsewhere, discouraging investments in efficiency. And actual efficiency gains have been widely eroded by the growth they have enabled, while many opportunities have remained untaken ${ }^{6}$, and cultural expectations of energy supply and services have expanded ${ }^{29}$. Fuel switching has similarly helped some countries reduce emissions intensities, but globally has tended to take the form of additional capacity rather than replacement, and sustaining the fossil economy in a shift to natural gas. Finally, CCS and BECCS remain negligible in practice, and largely diverted into enhanced oil recovery, while other negative emissions techniques remain unproven.

Some may respond nonetheless, that continued delays mean that more inventive ways of meeting our targets will be required. But in the current regime, each such novel technique or promise not only competes with existing ideas (in research funding, and in markets as much as in cost-optimising models), but also downplays any sense of urgency. Moreover this process also enables the repeated deferral of political deadlines for climate action which may in turn undermine societal commitment to meaningful responses ${ }^{30}$. It is perhaps a commonplace that politicians (and others) prefer to invoke technological fixes, rather than systemic change, whatever the challenge. Our concern is not only that politicians exaggerate technological promises to defuse pressure for other climate action, but also with the ways in which such technological promises are constructed in good faith by scientists and modellers, yet act to reframe or redefine targets in ways that delay action.

Most importantly, we suggest this history reveals that the contemporary climate engineering promises we began with are nothing unique. The exaggerated promise of BECCS - in which a largely imaginary technology with poorly understood impacts and resource demands was incorporated into models pushed to demonstrate the achievability of $450 \mathrm{ppm}$ (or $2^{\circ} \mathrm{C}$ ), but in turn enabled policy pathways based not only on high and ultimately unsustainable levels of BECCS promises but also on lowered mitigation rates ${ }^{18}$ was not a one-off problem, corrected by sound science, but a symptom of a chronic problem for climate policy. The promises of geoengineering technologies, through their apparent capacity to reverse concentrations or impacts, may more obviously enable prevarication, but conventional mitigation technologies are not exempt from the problem: layers of past unredeemed technological promises have become sedimented in climate pathway models. Contemporary imaginaries may prove just as unrealisable as the previous generations of promises. And there is no logical end to the set of possible technological promises that could be added to 'resolve' the models.

Today, climate policy is in flux, with debate over different ways to deliver temperature outcome goals (including increasing speculation around forms of geoengineering in the context of the IPCC's Sixth Assessment Review); over whether temperature goals are too simplistic as a measure of climate harm; and around policy framings of 'net-zero' and carbon-neutrality and the speed with which a transition to netzero needs to be (or could be) made. By drawing attention to the cycles of prevarication sketched here, we want to encourage more researchers to examine the potential relationship between climate delay, the emergence of new technological promises, and the repeated reframing of targets, and redrawing of modelling parameters. It is critical that problems arising in policy and target formulation are not treated naively and simply as knowledge deficits. There is scope for modellers to be more reflexive about how the risk of technology disappointment is represented in scenarios - both in single scenarios and across modelling efforts, and how such risk is communicated to policy makers. Scenarios which eschew overshoot logics could be a useful contribution ${ }^{31}$. More generally, we see a need for greater reflexivity over the processes by which targets are reframed, responses assessed, and models deployed ${ }^{32-34}$, extending to the ways in which the framings of policy and technology also reshape models, amongst other aspects of the broader cultural political economy of climate policy. 


\section{Financial Support}

The manuscript was written with support from grant NE/P019838/1 from the programme Greenhouse Gas Removal from the Atmosphere, funded by NERC, EPSRC, ESRC, BEIS, Met Office \& STFC in the UK.

\section{Acknowledgements}

Thanks are due to Andrew Jarvis for advice on the history of modelling, Simon Chew for assistance with the graphics, and to David Tyfield, Becky Willis and Bron Szerszynski for stimulating discussions and feedback. Some of this material was presented at the Negative Emissions Conference in Gothenburg in May 2018, and at the European Association for Studies of Science and Technology (EASST) conference in Lancaster in July 2018. We wish to thank participants at both events for their constructive feedback. We also wish to thank three anonymous reviewers for Nature Climate Change for their helpful comments.

\section{Author contributions}

DMcL wrote the manuscript, with support including written contributions from NM.

\section{References}

1 Rich, N. Losing Earth: A recent history. (MCD/Farrar, 2019).

2 UNFCCC. UN Framework Convention on Climate Change. (UN, Geneva, 1992).

3 Girod, B., Wiek, A., Mieg, H. \& Hulme, M. The evolution of the IPCC's emissions scenarios. Environmental Science \& Policy 12, 103-118, doi:https://doi.org/10.1016/j.envsci.2008.12.006 (2009).

$4 \quad$ IPCC. IPCC Special Report on Carbon Dioxide Capture and Storage. (Prepared by Working Group III of the Intergovernmental Panel on Climate Change Cambridge, 2005).

5 Markusson, N., Dahl Gjefsen, M., Stephens, J. C. \& Tyfield, D. The political economy of technical fixes: The (mis)alignment of clean fossil and political regimes. Energy Research \& Social Science 23, 1-10 (2017).

6 Lovins, A. B. How big is the energy efficiency resource? Environmental Research Letters 13, 090401, doi:10.1088/1748-9326/aad965 (2018).

$7 \quad$ Hansen, J. et al. Target Atmospheric CO2: Where Should Humanity Aim? The Open Atmospheric Science Journal 2, 217-231 (2008).

8 Azar, C., Lindgren, K., Larson, E. \& Möllersten, K. Carbon capture and storage from fossil fuels and biomass - costs and potential role in stabilizing the atmosphere. Climatic Change 74, 47-79 (2006).

9 Hansson, A. in The Social Dynamics of Carbon Capture and Storage (eds N. Markusson, S. Shackley, \& B. Evar) Ch. 5, 74-90 (Routledge/Earthscan, 2012).

10 Brunsting, S. et al. The Public and CCS: the Importance of Communication and Participation in the Context of Local Realities. Energy Procedia 4, 6241-6247 (2010).

11 Marien, N. Getting Action: COP Should Set Carbon Budgets for Real Progress, $<$ https://democracyctr.org/getting-action-cop-should-deliver-carbon-budgets-for-real-progress/> (2012).

12 Meinshausen, M. et al. The RCP greenhouse gas concentrations and their extensions from 1765 to 2300. Climatic Change 109, 213, doi:10.1007/s10584-011-0156-z (2011).

13 Moss, R. H., Nakicenovic, N. \& O'Neill, B. Towards New Scenarios for Analysis of Emissions, Climate Change, Impacts, and Response Strategies. (IPCC, Geneva, 2008).

14 Moss, R. H. et al. The next generation of scenarios for climate change research and assessment. Nature 463, 747, doi:10.1038/nature08823 (2010). 
Allen, M. R. et al. Warming caused by cumulative carbon emissions towards the trillionth tonne. Nature 458, 1163, doi:10.1038/nature08019 (2009).

16 Minx, J. C. et al. Negative emissions-Part 1: Research landscape and synthesis. Environmental Research Letters 13, 063001 (2018).

17 Blanford, G. J., Kriegler, E. \& Tavoni, M. Harmonization vs. fragmentation: overview of climate policy scenarios in EMF27. Climatic Change 123, 383-396, doi:10.1007/s10584-013-0951-9 (2014). Fuss, S. et al. Betting on negative emissions. Nature Climate Change 4, 850, doi:10.1038/nclimate2392 (2014). Muri, $\mathrm{H}$. The role of large-scale BECCS in the pursuit of the $1.5^{\circ} \mathrm{C}$ target: an Earth system model perspective. Environmental Research Letters 13, 044010 (2018). Jaeger, C. C. \& Jaeger, J. Three views of two degrees. Regional Environmental Change 11, 15-26, doi:10.1007/s10113-010-0190-9 (2011).

Realmonte, G. et al. An inter-model assessment of the role of direct air capture in deep mitigation pathways. Nature communications 10, 3277, doi:10.1038/s41467-019-10842-5 (2019). Bastin, J.-F. et al. The global tree restoration potential. Science 365, 76, doi:10.1126/science.aax0848 (2019). President's Science Advisory Committee (PSAC). Restoring the Quality of our Environment: Report of the Environmental Pollution Panel. (The White House, Washington DC, 1965). Irvine, P. et al. Halving warming with idealized solar geoengineering moderates key climate hazards. Nature Climate Change 9, 295-299, doi:10.1038/s41558-019-0398-8 (2019). Stilgoe, J. Experiment Earth: Responsible Innovation in Geoengineering. (Routledge/Earthscan, 2015).

27 Markusson, N., McLaren, D. \& Tyfield, D. Towards a cultural political economy of mitigation deterrence by negative emissions technologies (NETs). Global Sustainability 1, e10, doi:10.1017/sus.2018.10 (2018). Mitchell, T. Carbon Democracy, Political Power in the Age of Oil. (Verso, 2011). Shove, E. What is wrong with energy efficiency? Building Research \& Information 46, 779-789, doi:10.1080/09613218.2017.1361746 (2018). Asayama, S., Bellamy, R., Geden, O., Pearce, W. \& Hulme, M. Why setting a climate deadline is dangerous. Nature Climate Change 9, 570-572, doi:10.1038/s41558-019-0543-4 (2019). Rogelj, J. et al. A new scenario logic for the Paris Agreement long-term temperature goal. Nature 573, 357-363, doi:10.1038/s41586-019-1541-4 (2019). Anderson, K. \& Jewell, J. Debating the bedrock of climate-change mitigation scenarios. Nature 573, 348-349 (2019).

Beck, S. \& Mahony, M. The IPCC and the new map of science and politics. Wiley Interdisciplinary Reviews: Climate Change 9, e547, doi:10.1002/wcc.547 (2018). technologies experience. Global Sustainability 1, e8, doi:10.1017/sus.2018.7 (2018). 


\section{Figure 1: Schematic representation of phases in climate policy, describing the co-evolution of four key elements: climate politics, policy targets and framings, modelling methods and scenarios, and technological promises.}

The panels illustrate five phases (a-e) of climate policy from around 1990 to present, located in time by reference to key events in climate policy and politics, notably international negotiations that shaped public debate (pink quadrants). The green quadrants highlight the predominant framings of policy targets and the metrics applied. The yellow quadrants indicate the contemporary technological promises, innovations and future proposals for deployment at scale. The blue quadrants describe the state of and advances in climate modelling methods, and the scenarios used to inform policy. In each panel, the surrounding grey boxes elaborate on the quadrant descriptions and further illustrate aspects of coevolution. The arrows indicate all of the possible relationships between the key elements indicated in the quadrants.

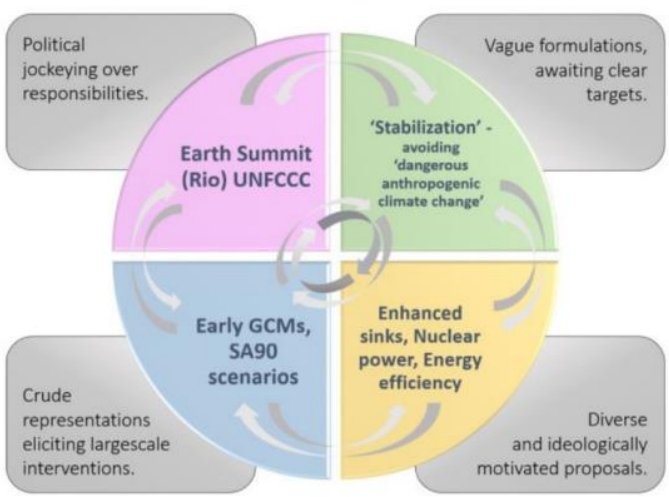

(a) Phase 1- Stabilization

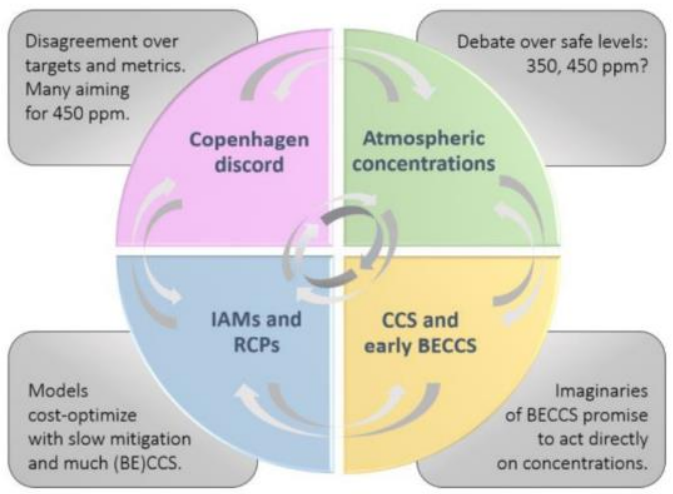

(c) Phase 3-Atmospheric concentrations

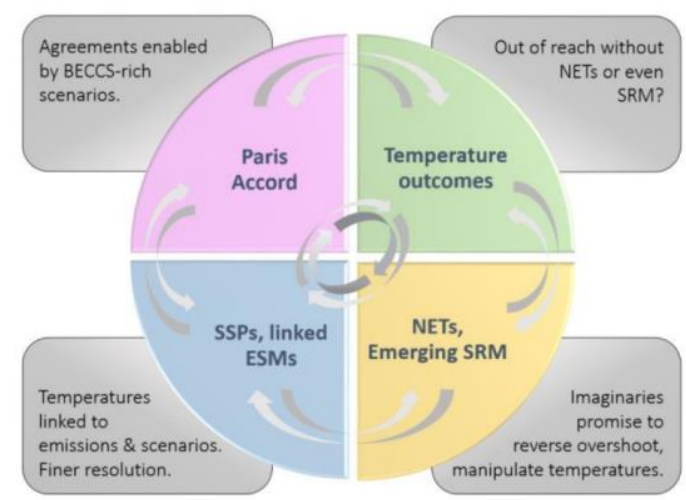

(e) Phase 5-Outcome temperatures

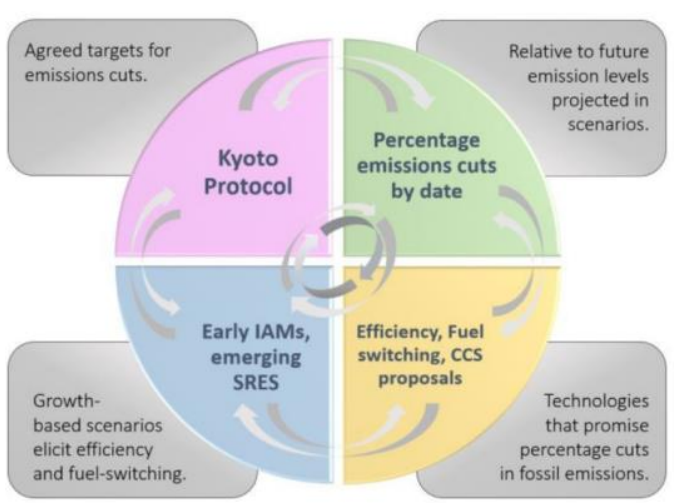

(b) Phase 2-Percentage emissions cuts

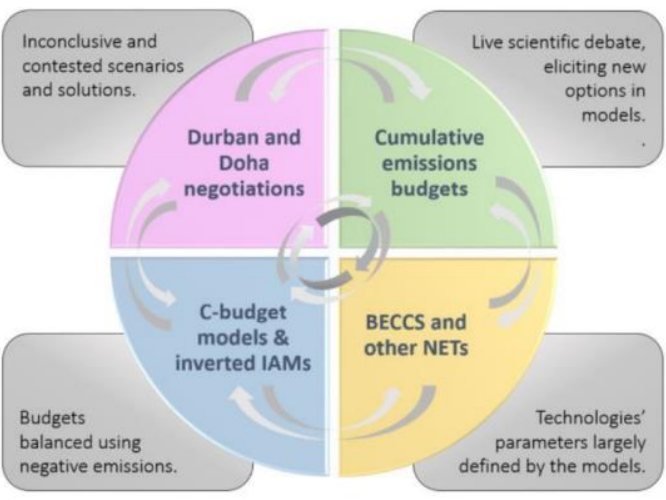

(d) Phase 4-Cumulative budgets 